\title{
Enhanced photocatalytic hydrogen production activity of highly crystalline carbon nitride synthesized by hydrochloric acid treatment
}

\author{
Yang Li ${ }^{\text {a,b }}$, Dainan Zhang a, Xionghan Feng b, Quanjun Xiang a,* \\ a State Key Laboratory of Electronic Thin Film and Integrated Devices, School of Electronic Science and Engineering, University of Electronic Science and \\ Technology of China, Chengdu 610054, Sichuan, China \\ ${ }^{\mathrm{b}}$ College of Resources and Environment, Huazhong Agricultural University, Wuhan 430070, Sichuan, China
}

\section{A R T I C L E I N F O}

\section{Article history:}

Received 30 April 2019

Accepted 27 May 2019

Published 5 January 2020

Keywords:

Crystalline carbon nitride

Molten-salt method

Photocatalytic hydrogen evolution

Potassium ions

Aqueous hydrochloric acid solution

\begin{abstract}
A B S T R A C T
Crystalline carbon nitride (CCN) prepared by a molten-salt method is attracting increased attention because of its promising properties and excellent photocatalytic activity. In this work, we further improve the crystallinity of CCN through synthesis by the molten-salt method under the action of aqueous hydrochloric acid $(\mathrm{HCl})$ solution. Our results showed that the crystallinity of the as-prepared samples increased with increasing $\mathrm{HCl}$ concentration and reached the maximum value at $0.1 \mathrm{~mol} \mathrm{~L}^{-1}$. This can be attributed to the removal of some potassium ions $\left(\mathrm{K}^{+}\right)$from the terminal amino groups of $\mathrm{CCN}$ by the aqueous $\mathrm{HCl}$ solution, which results in a release of the polymerization sites. As a result, the crystallinity of the as-prepared samples further increased. Moreover, the obtained 0.1 highly crystalline carbon nitride $\left(0.1 \mathrm{HCCN}\right.$; treated with $0.1 \mathrm{~mol} \mathrm{~L}^{-1}$ aqueous $\mathrm{HCl}$ solution) exhibited an excellent photocatalytic hydrogen evolution of $683.54 \mu \mathrm{mol} \mathrm{h}^{-1} \mathrm{~g}^{-1}$ and a quantum efficiency of $6.6 \%$ at $420 \mathrm{~nm}$ with triethanolamine as the sacrificial agent. This photocatalytic hydrogen evolution was 2 and 10 times higher than those of CCN and bulk carbon nitride, respectively. The enhanced photocatalytic activity was attributed to the improved crystallinity and intercalation of $\mathrm{K}^{+}$into the $x \mathrm{HCCN}$ interlayer. The improved crystallinity can decrease the number of surface defects and hydrogen bonds in the as-prepared sample, thereby increasing the mobility of the photoinduced carriers and reducing the recombination sites of the electron-hole pairs. The $\mathrm{K}^{+}$intercalated into the $x \mathrm{HCCN}$ interlayer also promoted the transfer of the photoinduced electrons because these ions can increase the electronic delocalization and extend the $\pi$-conjugated systems. This study may provide new insights into the further development of the molten-salt method.
\end{abstract}

(C) 2020, Dalian Institute of Chemical Physics, Chinese Academy of Sciences. Published by Elsevier B.V. All rights reserved.

\section{Introduction}

Photocatalytic water splitting into hydrogen is considered as an ideal way to address the environmental and global energy problems because of the high energy density and zero pollution characteristics of hydrogen [1-9]. Since the successful application of graphitic carbon nitride $\left(\mathrm{g}-\mathrm{C}_{3} \mathrm{~N}_{4}\right)$ polymer in the field of photocatalysis in 2009 [10], this metal-free photocatalyst has attracted considerable attention because of its chemical stability, accessibility, low cost, and nontoxicity [11-17]. However,

\footnotetext{
* Corresponding author. Tel/Fax: +86-28-83207063; E-mail: xiangqj@uestc.edu.cn This work was supported by the National Natural Science Foundation of China (51672099, 21403079), Sichuan Science and Technology Program (2019JDRC0027), and Fundamental Research Funds for the Central Universities (2017-QR-25).

DOI: S1872-2067(19)63427-3 | http://www.sciencedirect.com/science/journal/18722067 | Chin. J. Catal., Vol. 41, No. 1, January 2020
} 
g- $\mathrm{C}_{3} \mathrm{~N}_{4}$ obtained by conventional thermal polymerization of nitrogen-containing precursors presents an amorphous or semi-crystalline structure and a poor photocatalytic activity because the nitrogen-containing precursors are incompletely polymerized, which results in massive residual amino groups in the amorphous or semi-crystalline carbon nitrogen $(\mathrm{CN})$ during the condensation process. Moreover, the abundance of hydrogen bonds in the amorphous or semi-crystalline CN framework increases the recombination centers for the charge carriers. These factors are the main cause of the moderate photocatalytic performance of $\mathrm{g}-\mathrm{C}_{3} \mathrm{~N}_{4}$. [18,19].

To address these issues, various strategies such as molten-salt method [20,21], microwave-assisted synthesis [22,23], and some other methods [24-28] have been proposed for the synthesis of crystalline carbon nitride (CCN). Among these, molten-salt method is widely used because it is convenient, environment friendly, and powerful [29]. At present, the CCN prepared by molten-salt method can be divided into two types: poly (triazine imides) (PTI) and poly (heptazine imides) (PHI). The photocatalytic activity of PHI is superior to that of PTI owing to the presence of a larger $\pi$-conjugated system in the heptazine unit, which is favorable for optical absorption and promotes the mobility of photoinduced carriers [30,31]. For instance, Zeng et al. [32] designed highly crystalline CCN with triazine (CCN $\mathrm{CTI}$ ) and heptazine subunits ( $\left.\mathrm{CCN}_{\mathrm{PHI}}\right)$ by molten-salt method. As expected, the photocatalytic hydrogen evolution of CCNPHI is considerably higher than that of CCNPTI because of the low light-harvesting capability and limited extension of the aromatic rings of CCN PTI. However, the intensity of the (002) facets of the prepared CCNPHI is always lower than that of bulk carbon nitride (BCN) and its crystallinity is still not satisfactory [33], even if the prepared $\mathrm{CCN}_{\mathrm{PHI}}$ shows a good photocatalytic activity. Moreover, the CCN prepared by molten-salt method contains a certain amount of $\mathrm{K}^{+}$[34]. Most of the literature reports have pointed out that $\mathrm{K}^{+}$can promote the photocatalytic activity of $\mathrm{CCN}$, but no specific research on $\mathrm{K}^{+}$ has been carried out or reported.

In this work, we report a facile method to synthesize highly crystalline carbon nitride (HCCN) based on molten-salt method by aqueous $\mathrm{HCl}$ solution treatment. The obtained $0.1 \mathrm{HCCN}$ (under the treatment of $0.1 \mathrm{~mol} \mathrm{~L}^{-1}$ aqueous $\mathrm{HCl}$ solution) exhibited optimum crystallinity and an appropriate concentration of $\mathrm{K}^{+}$, compared with those of the other samples. The excellent crystallinity can decrease the surface defects and hydrogen bonds in the as-prepared sample, which increases the mobility of the photoinduced carriers and reduces the recombination sites of the electron-hole pairs. Moreover, the $\mathrm{K}^{+}$intercalated into the $x \mathrm{HCCN}$ interlayer also promote the transfer of photoinduced electrons because they can increase the electronic delocalization and extend the $\pi$-conjugated systems. Owing to these features, 0.1HCCN showed an excellent photocatalytic hydrogen evolution of $683.54 \mu \mathrm{mol} \mathrm{h}^{-1} \mathrm{~g}^{-1}$ and a quantum efficiency of $6.6 \%$ at $420 \mathrm{~nm}$ with triethanolamine (TEOA) as the sacrificial agent. This represents a photocatalytic hydrogen evolution rate (HER) that is approximately 2 and 10 times higher than those of CCN and BCN, respectively.

\section{Experimental}

\subsection{Materials}

The melamine $\left(\mathrm{C}_{3} \mathrm{H}_{6} \mathrm{~N}_{6}, 99 \%\right), \quad \mathrm{HCl} \quad(36 \%-38 \%), \quad \mathrm{KCl}$ (99.5\%), and $\mathrm{LiCl}(97 \%)$ used were of analytical grade and employed without further purification. Deionized water was used in all the experiments.

\subsection{Sample preparation}

CCN was synthesized in accordance with previous studies. In brief, $8 \mathrm{~g}$ of melamine was heated to $500{ }^{\circ} \mathrm{C}$ for $4 \mathrm{~h}$ at a rate of $12{ }^{\circ} \mathrm{C} \mathrm{min}-1$ under air atmosphere. Subsequently, the light-yellow product $(600 \mathrm{mg}$ ) obtained was ground with $\mathrm{KCl}$ ( $3.3 \mathrm{~g}$ ) and $\mathrm{LiCl}$ ( $2.7 \mathrm{~g}$ ) in a crucible. Then, the mixture was heated to $550{ }^{\circ} \mathrm{C}$ for 4 at a rate of $5{ }^{\circ} \mathrm{C} \mathrm{min}^{-1}$ under $\mathrm{N}_{2}$ atmosphere in a muffle furnace. The product was washed with boiling water and collected after drying overnight at $60^{\circ} \mathrm{C}$ in an oven. The obtained sample was referred to as CCN. Finally, the obtained CCN (100 mg) was disposed with $\mathrm{HCl}$ solution $(0.005$, $0.01,0.1$, and $0.2 \mathrm{~mol} \mathrm{~L}^{-1}$ ) and stirred for $1 \mathrm{~h}$. The final products were washed with deionized water and collected after drying overnight at $60{ }^{\circ} \mathrm{C}$ in an oven. The products were labeled as $x$ HCCN, where $x$ refers to $0.005,0.01,0.1$, and 0.2 (the concentration of the $\mathrm{HCl}$ solution in moles per liter).

\subsection{Characterization}

The XRD patterns were recorded on a D8-Advance diffractometer (Bruker, German) with nickel-filtered $\mathrm{Cu} K_{\alpha}$ radiation at a scan rate $(2 \theta)$ of $10^{\circ} \mathrm{min}^{-1}$, an accelerating voltage of 40 $\mathrm{kV}$, and a current of $40 \mathrm{~mA}$. The TEM images were obtained using a Hitachi H-7650 (HITACHI, Japan) transmission electron microscope at an accelerating voltage of $200 \mathrm{kV}$, and HRTEM analysis was performed with a JEM-2100F (JEOL, Japan) microscope. The SEM images were recorded on an S-4800 (HITACHI, Japan) instrument. The UV-vis diffuse reflectance spectra (DRS) were obtained using a UV-vis spectrophotometer (Lambda 650s), and Teflon was used as the reflectance standard. The X-ray photoelectron spectroscopy (XPS) spectra were obtained with the help of a Leybold Heraeus-Shenyang SKL-12 $\mathrm{X}$-ray photoelectron spectrometer, and $\mathrm{Mg} K_{\alpha}$ served as the excitation source. The electron paramagnetic resonance (EPR) spectra were obtained using a suitable spectrometer (Bruker, German) at room temperature. The time-resolved fluorescence decay spectra were recorded at room temperature on a fluorescence spectrophotometer (Edinburgh, FS5).

The photocatalytic $\mathrm{H}_{2}$ productions of the obtained photocatalysts were measured in a $100 \mathrm{~mL}$ three-necked flask at atmospheric pressure and room temperature. A $350 \mathrm{~W}$ xenon arc lamp was utilized as the light source and aqueous $10 \%$ TEOA solution (by volume) was used as the sacrificial agent. The details of the steps involved are as follow. $20 \mathrm{mg}$ of the samples were dispersed in $80 \mathrm{~mL}$ of the sacrificial agent by loading $3 \%$ platinum as the co-catalyst. The suspension solution of the mixture of photocatalysts was degassed with $\mathrm{N}_{2}$ for 
30 min to remove the remaining $\mathrm{O}_{2}$ and air in the flask. After 1 $\mathrm{h}$ of illumination, $0.4 \mathrm{~mL}$ of gas was extracted, which was detected with a gas chromatograph (GC-2004C, Japan).

The wavelength-dependent HERs of TF samples were determined through a method similar to that of photocatalytic $\mathrm{H}_{2}$ production, except for the xenon arc lamp being replaced with an LED equipped with different monochromatic lights. The averaged irradiation intensity of the different monochromatic lights realized by controlling the internal power was $80 \mathrm{~mW}$ $\mathrm{cm}^{-2}$. QE was obtained using the Nether equation: $\mathrm{QE}=$ number of reacted electrons $\div$ number of incident photons $\times 100 \%=$ number of evolved $\mathrm{H}_{2}$ molecules $\times 2 \div$ number of incident photons $\times 100 \%$.

The photocurrent curves and the electrochemical impedance spectroscopy (EIS) patterns were obtained by using a CHI660E (Shanghai Chenhua Limited, China) electrochemical analyzer with a three-electrode system that employs a platinum wire and $\mathrm{Ag} / \mathrm{AgCl}$ as the counter and reference electrodes, respectively. The working electrodes were prepared glass electrodes with an effective area of ca. $1.0 \mathrm{~cm}^{2}$. A $350 \mathrm{~W}$ xenon arc lamp and $0.5 \mathrm{~mol} \mathrm{~L}^{-1}$ aqueous $\mathrm{Na}_{2} \mathrm{SO}_{4}$ solution were used as the light source and electrolyte, respectively.

The glass working electrode was synthesized as follows. A mixture of $0.02 \mathrm{~g}$ of the sample, $0.02 \mathrm{~g}$ of polyethyleneglycol, and $0.5 \mathrm{~mL}$ of ethanol was ground into a slurry. Doctor blade method was used to evenly coat the slurry onto a $2 \mathrm{~cm} \times 1.2 \mathrm{~cm}$ fluorine-doped $\mathrm{SnO}_{2}$-coated glass electrode. Finally, the obtained glass electrodes were dried at $100{ }^{\circ} \mathrm{C}$ for $60 \mathrm{~min}$ in an oven.

\section{Results and discussion}

\subsection{Structure and morphology of the samples}

The X-ray diffraction (XRD) patterns of the samples are shown in Fig. 1. For BCN, the peak at $27.8^{\circ}$ (indexed as (002)) was assigned to the layered stacking of heptazine frameworks. The peak at $13.1^{\circ}$ (indexed as (100)) was attributed to the in-plane structure [35-37]. However, two main peaks located at $8.1^{\circ}$ and $28.3^{\circ}$ were found for CCN. The former peak shifted to a lower angle, compared to those of BCN, because of the enlarged in-plane repeating motifs [38]. The latter peak shifted from $27.4^{\circ}$ to $28.3^{\circ}$, which corresponded to a decreased inter- layer distance [33]. In the case of $x \mathrm{HCCN}$, the weak peak at $8.1^{\circ}$ can be observed in all the samples and does not significantly change compared with that of CCN. However, the (002) peak intensity and position increased and shifted to a larger degree with an increase in the concentration of the aqueous $\mathrm{HCl}$ solution from 0.005 to $0.1 \mathrm{~mol} \mathrm{~L}^{-1}$. This phenomenon indicated that the interlayer distance in $x \mathrm{HCCN}$ decreases with the increase in the concentration of the aqueous $\mathrm{HCl}$ solution from 0.005 to $0.1 \mathrm{~mol} \mathrm{~L}^{-1}$, which can be attributed to the enhanced interaction between the layers. Interestingly, when the concentration of the $\mathrm{HCl}$ solution is up to $0.2 \mathrm{~mol} \mathrm{~L}^{-1}$, the (002) peak intensity of $0.2 \mathrm{HCCN}$ decreases, compared with that of $0.1 \mathrm{HCCN}$. This phenomenon may be attributed to destruction of the structure of the CN framework [39]. As a comparison, the XRD pattern of BCN obtained after treatment with aqueous $\mathrm{HCl}$ solution is displayed in Fig. S1. The sharply weakened (002) peak confirms the destruction of the structure of $\mathrm{CN}$. Moreover, the full width at half maximum (FWHM) of the (002) peaks of CCN and $x$ HCCN is narrower than that of BCN (Fig. 1b), which suggests high crystallinities of $\mathrm{CCN}$ and $x \mathrm{HCCN}$. Moreover, the narrowest FWHM can be found in $0.1 \mathrm{HCCN}$, which indicates that $0.1 \mathrm{HCCN}$ exhibits the highest crystallinity among these samples.

The chemical compositions of BCN, CCN, and $x \mathrm{HCCN}$ were further identified by FTIR spectroscopy. As shown in Fig. 2a, peaks at 3000-3500, 1200-1700, and $810 \mathrm{~cm}^{-1}$ appear for $\mathrm{BCN}$; these peaks are attributed to the terminal amino group, C-N stretching vibrations, and bending mode of heptazine, respectively [42-46]. The FTIR spectra of CCN and $x$ HCCN are similar to that of BCN, which suggests that the molten-salt method and $\mathrm{HCl}$ treatment do not change the main structure of the $\mathrm{CN}$ framework. Further, a decrease in the intensity of the peak at $3000-3500 \mathrm{~cm}^{-1}$ can be observed in the cases of CCN and $x \mathrm{HCCN}$, compared with that in the case of BCN, which indicates that the ammonia content decreases in CCN and $x$ HCCN. This result was further confirmed by the appearance of a new peak at $2150 \mathrm{~cm}^{-1}$ for $\mathrm{CCN}$ and $x \mathrm{HCCN}$ that was ascribed to the existence of terminal cyano groups. Moreover, the formation of cyano groups can affect the light harvesting and charge separation, which are beneficial to the photocatalytic reaction of CCN and $x$ HCCN $[47,48]$.

The optical absorptions of BCN, CCN, and $x$ HCCN were characterized based on their UV-vis DRS. As shown in Fig. 2b, all the samples reveal the typical absorption curve of semicon-
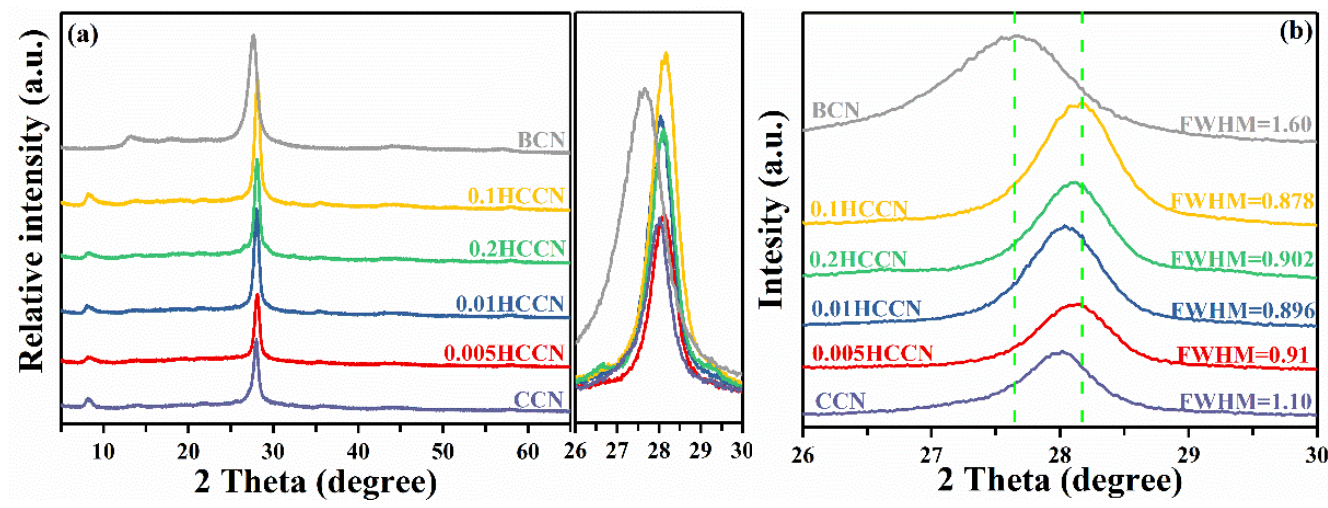

Fig. 1. (a) XRD patterns and (b) FWHMs of as-prepared BCN, CCN, and $x H C C N$. 

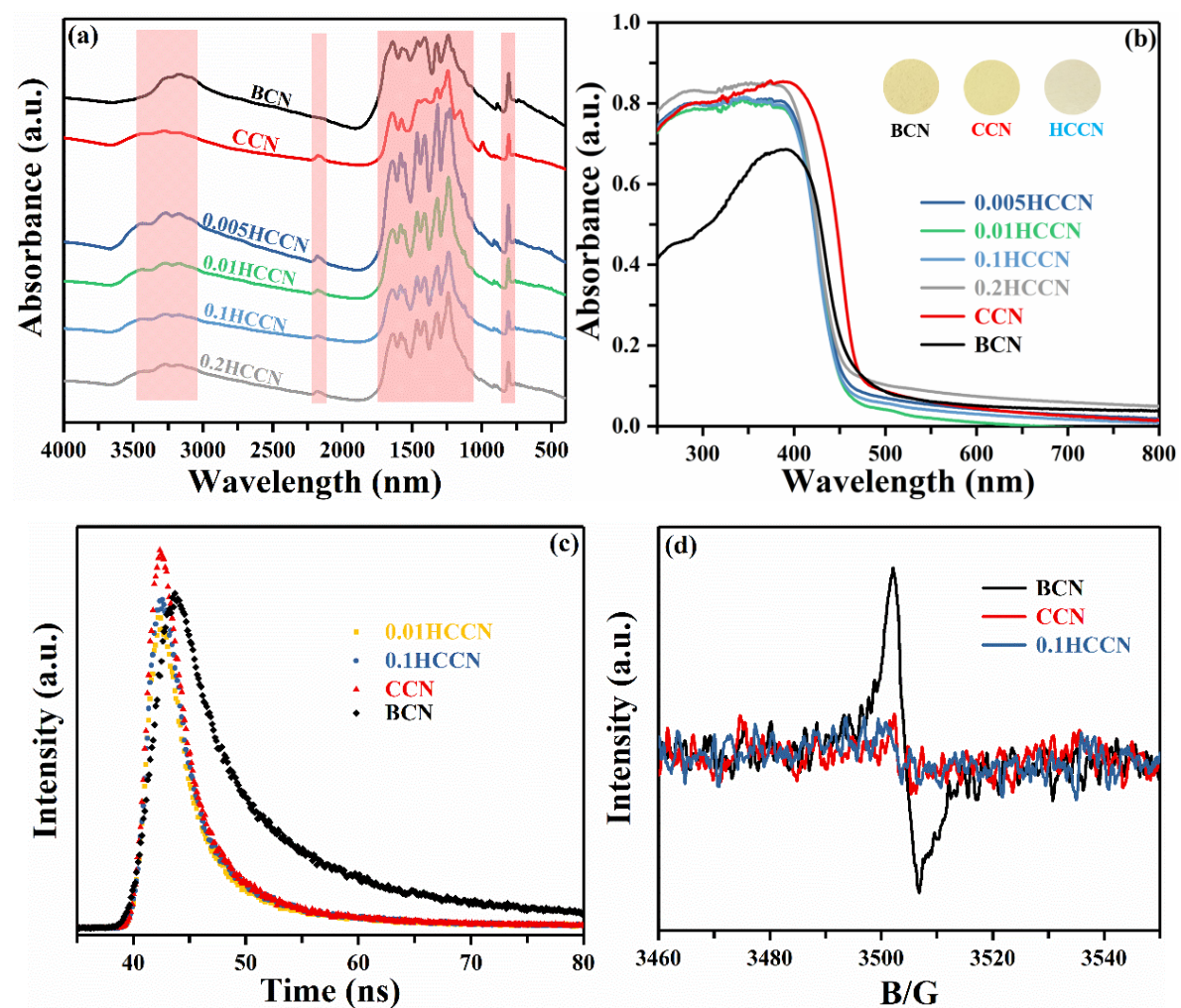

Fig. 2. (a) FTIR spectra and (b) UV-vis DRS of as-prepared BCN, CCN, and $x$ HCCN (inset shows the colors of BCN, CCN, and HCCN); (c) Time-resolved photoluminescence (PL) spectra of 0.01HCCN, 0.1HCCN, CCN, and BCN; (d) EPR spectra of BCN, CCN, and 0.1HCCN.

ductors. As expected, the optical absorption intensities of CCN and $x \mathrm{HCCN}$ were significantly higher than that of $\mathrm{BCN}$, because of the crystallinity and the existence of cyano groups in CCN and $x$ HCCN. This result matched well with the XRD and FTIR results. This finding is beneficial for the photocatalytic activity because a higher optical absorption can lead to a greater number of photons being utilized in the photocatalytic reaction. Moreover, the absorption edge of CCN exhibited a red shift in comparison with that of BCN, which may be attributed to the doping of $\mathrm{K}^{+}$in $\mathrm{CCN}$ during the preparation process. Moreover, the absorption edges of $x \mathrm{HCCN}$ displayed a blue shift, compared with that of $\mathrm{CCN}$, because of the decreased $\mathrm{K}^{+}$contents of $x \mathrm{HCCN}$ during the $\mathrm{HCl}$ treatment. The bandgap energies were 2.7, 2.74, and $2.8 \mathrm{eV}$ for $\mathrm{CCN}, \mathrm{BCN}$, and $0.1 \mathrm{HCCN}$, respectively, and were estimated from the respective Tauc plots (Fig. S2). In fact, the bandgap slightly differed from that of $x \mathrm{HCCN}$ owing to the differences in the $\mathrm{K}^{+}$concentration and crystallinity.

The time-resolved fluorescence spectra were also obtained to confirm the efficiency of electron-hole pair separation and migration. As shown in Fig. 2c, BCN exhibits a slower PL decay, compared with those of CCN and $x \mathrm{HCCN}$ (where $x=0.01$ and 0.1 ), which show similar decay rates. The radiative lifetimes and the related parameters of the fitted decay spectra are listed in Table 1. The average lifetime of $16.487 \mathrm{~ns}$ for $0.1 \mathrm{HCCN}$ was notably shorter than those of BCN (19.819 ns) and CCN (16.571 ns). The reduced average lifetime of $0.1 \mathrm{HCCN}$, which indicates effective migration of charge carriers, was very beneficial for photocatalytic reactions [49,50]. This result was further proven by the EPR spectra. As shown in Fig. 2d, three samples display a single peak centered at a g-value of 2.0034, which indicates the existence of unpaired electrons in the $s p^{2}$ carbon in the $\pi$-conjugated aromatic rings [51-53]. Notably, the peak intensity of $0.1 \mathrm{HCCN}$ was lower than that of BCN. The decreased lone-pair electron density may be attributed to the high crystallinity and low surface-defect density of 0.1 HCCN [54]. In general, surface defects can be considered as recombination centers that limit carrier separation and thereby reduce the photocatalytic activity. These results confirmed that the separation and migration of charge carriers in 0.1HCCN are superior to those in BCN and CCN.

The morphologies of the as-prepared samples were investigated by SEM. As shown in Fig. 3, BCN exhibits a stacking layered structure, whereas $\mathrm{CCN}$ and $x \mathrm{HCCN}$ reveal nanorod structures. Notably, the nanorod structure of the $x \mathrm{HCCN}$ samples

Table 1

Fluorescence decay lifetimes and percentages of photoinduced carriers in pristine BCN, CCN, and 0.1 HCCN.

\begin{tabular}{lccccccc}
\hline Sample & $\tau_{1} / \mathrm{ns}$ & $A_{1} / \%$ & $\tau_{2} / \mathrm{ns}$ & $A_{2} / \%$ & $\tau_{3} / \mathrm{ns}$ & $A_{3} / \%$ & $\tau / \mathrm{ns}$ \\
\hline BCN & 3.530 & 29.388 & 10.968 & 40.093 & 47.131 & 30.519 & 19.819 \\
CCN & 2.992 & 19.871 & 8.312 & 41.437 & 32.389 & 38.692 & 16.571 \\
$0.1 \mathrm{HCCN}$ & 2.766 & 17.038 & 7.867 & 43.196 & 32.215 & 39.766 & 16.487 \\
\hline
\end{tabular}




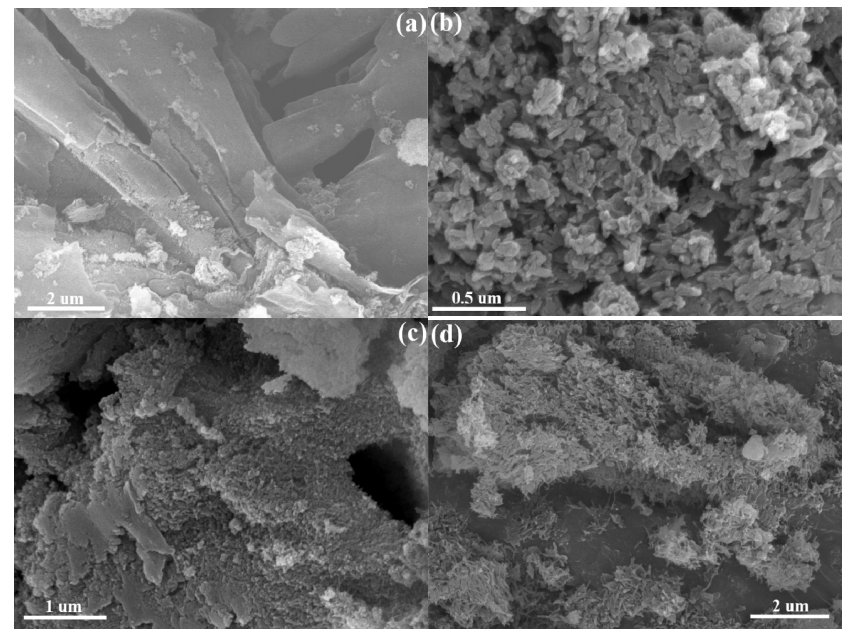

Fig. 3. SEM images of (a) BCN, (b) CCN, (c) $0.01 \mathrm{HCCN}$, and (d) $0.1 \mathrm{HCCN}$.

becomes clearer with an increase in the $\mathrm{HCl}$ concentration. The crystalline structure of the as-prepared samples was further confirmed by TEM. As shown in Fig. $4 \mathrm{a}$ and $4 \mathrm{~b}$, the nanorod structures of CCN and $x \mathrm{HCCN}$ can be observed using the TEM images. Lattice fringes of spacing $0.33 \mathrm{~nm}$ are clearly observed on CCN and $x$ HCCN in Fig. 4c and 4d, which strongly supports the idea that their structure is crystalline. However, the lattice fringe of BCN is not observed in Fig. S3, which indicates that the structure of BCN is amorphous. These results well agreed with the XRD results, which revealed the planar diffraction distances.

The elemental compositions of $0.1 \mathrm{HCCN}$ and $0.01 \mathrm{HCCN}$ were obtained by XPS. As shown in Fig. 5a, 0.1HCCN and 0.01HCCN exhibit similar survey spectra. Obviously, carbon, nitrogen, oxygen, and potassium elements can be detected from the two curves. The additional oxygen atom signals originated from the absorbed $\mathrm{H}_{2} \mathrm{O}$ or $\mathrm{O}_{2}$ molecules [55]. The high-resolution XPS C $1 s, \mathrm{~N} 1 s$, and $\mathrm{K} 2 p$ spectra of $0.01 \mathrm{HCCN}$ and $0.1 \mathrm{HCCN}$ are shown in Figs. $5 \mathrm{~b}-5 \mathrm{~d}$, respectively. Different peaks at 288.5, 286.4, and $284.8 \mathrm{eV}$ can be observed in the high-resolution C $1 s$ (Fig. 5b) spectrum that probably originat-

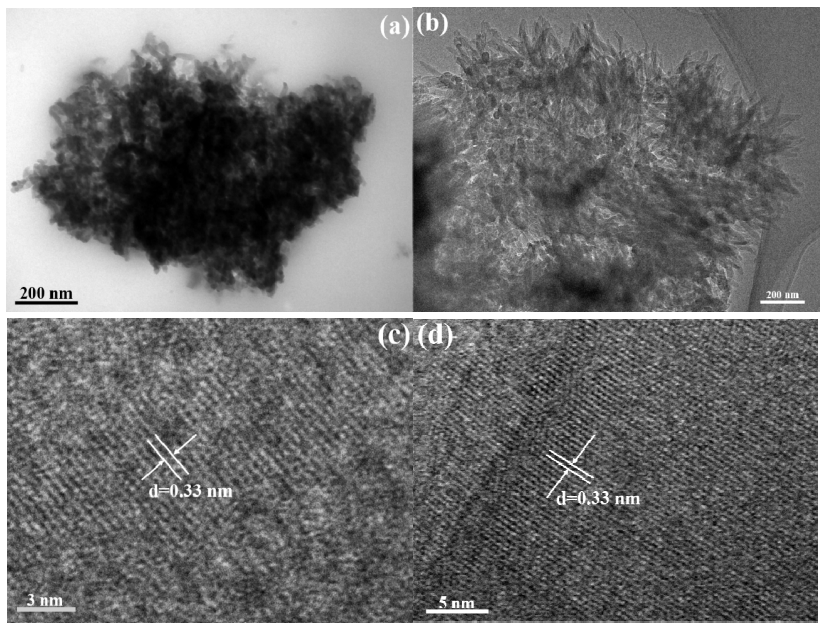

Fig. 4. (a, b) TEM and (c, d) HRTEM images of (a, c) CCN and (b, d) $0.1 \mathrm{HCCN}$ ed from the $s p^{2}$ bonds of the nitrogen-containing heptazine rings $(\mathrm{N}-\mathrm{C}=\mathrm{N})$, cyano group, and adventitious carbon, respectively [56,57]. In the high-resolution $\mathrm{N} 1 \mathrm{~s}$ spectrum of $0.01 \mathrm{HCCN}$, four peaks are observed at 404.4, 401.6, 400.7, and $398.9 \mathrm{eV}$. The peaks at $404.4,401.6$, and $398.9 \mathrm{eV}$ were attributed to the $\pi$ excitation, tertiary nitrogen, and heptazine rings $(\mathrm{C}-\mathrm{N}=\mathrm{C})\left(\mathrm{NC}_{3}\right)$ [58], respectively, whereas the peak at $400.7 \mathrm{eV}$ was assigned to the terminal amino groups [59]. In the high-resolution $\mathrm{N} 1 \mathrm{~s}$ spectrum of $0.1 \mathrm{HCCN}$, three similar peaks at 404.4, 401.6, and $398.9 \mathrm{eV}$ can be observed. However, an obvious shift of the peak at $400.4 \mathrm{eV}$ is observed relative to that of $0.01 \mathrm{HCCN}$. The peak shift observed for the terminal amino groups indicates strong effects between the nitrogen and potassium atoms. $\mathrm{K} 2 p$ peaks also appear in the sample spectra. As a comparison, the XPS spectrum of CCN was also recorded (Fig. S5). As shown in Fig. S5d and S5d, the K state is almost the same before and after the $\mathrm{HCl}$ treatment. These results may be attributed to the $\mathrm{K}^{+}$acting as charge compensators that replace the hydrogen ions in the terminal amino groups formed due to the breakage of the hydrogen bonds in BCN [60]. However, the concentration of $\mathrm{K}^{+}$changes from $2.63 \%$ in CCN to $0.81 \%$ in $0.01 \mathrm{HCCN}$ and $0.57 \%$ in $0.1 \mathrm{HCCN}$ owing to the instability of the terminal $\mathrm{K}-\mathrm{N}$, which proves that increasing the concentration of $\mathrm{HCl}$ can gradually decrease the concentration of $\mathrm{K}^{+}$. These results confirm that $\mathrm{HCl}$ treatment only changes the concentration of $\mathrm{K}^{+}$and not the structure of the sample.

\subsection{Formation mechanism}

Based on the above characterization results, a possible formation mechanism of $x \mathrm{HCCN}$ is shown in Fig. 6. The synthesis process was divided into three steps. In the first step $\left(500{ }^{\circ} \mathrm{C}, 4\right.$ $\mathrm{h})$, the melamine molecules polymerized to form heptazine nitride $\mathrm{CN}$ frameworks with massive hydrogen bonds and amino groups. In the second step $\left(550{ }^{\circ} \mathrm{C}, 4 \mathrm{~h}\right)$, the solid $\mathrm{KCl} / \mathrm{LiCl}$ mixture (melting point: $450{ }^{\circ} \mathrm{C}$ ) melted to provide a liquid medium for heptazine $\mathrm{CN}$. Under this condition, some of the $\mathrm{K}^{+}$acted as charge compensators to replace the hydrogen ions of the terminal amino groups that were formed due to the breakage of the hydrogen bonds in BCN. Another $\mathrm{K}^{+}$was doped into the heptazine interlayer, which resulted in the formation of CCN with a massive amount of $\mathrm{K}^{+}$. However, unsatisfactory crystallinity was observed in $\mathrm{CCN}$ when the $\mathrm{K}^{+}$in the terminal amino groups of CCN occupied some polymerization sites of the heptazine unit. In the last step ( $\mathrm{HCl}$ treatment), under the influence of $\mathrm{HCl}$, some of the $\mathrm{K}^{+}$in the terminal amino groups of CCN were removed and the polymerization sites released, which further enhanced the crystallinity of CCN.

\subsection{Photoelectrochemical performances of the samples}

Photoelectrochemical measurements were used to further investigate the separation and migration of the photogenerated carriers. The photocurrent curves of 0.01HCCN, 0.1HCCN, CCN, and BCN are shown in Fig. 7a. Among these samples, 0.1HCCN exhibited the highest photocurrent density owing to its high 

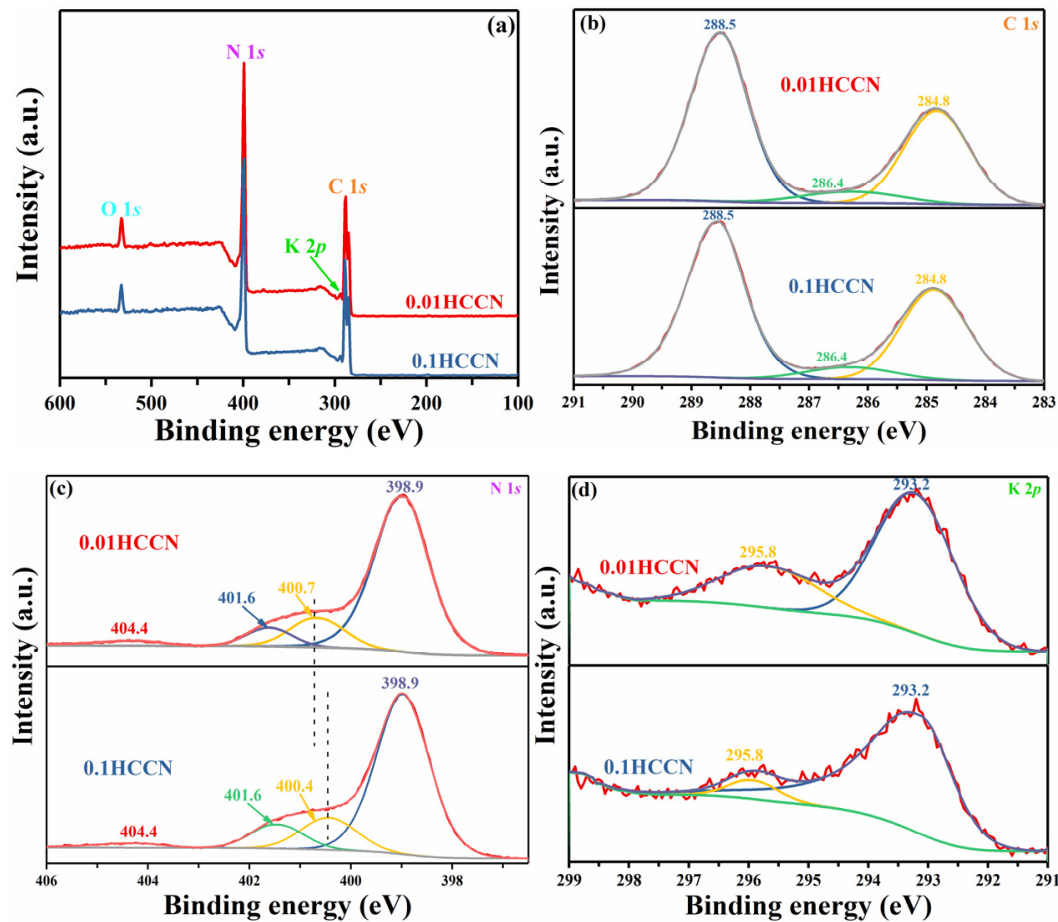

Fig. 5. (a) XPS survey spectra, (b) C $1 s$, (c) N $1 s$, and (d) K $2 p$ spectra of $0.01 \mathrm{HCCN}$ and $0.1 \mathrm{HCCN}$. The XPS spectra show that the elemental compositions of $0.01 \mathrm{HCCN}$ and $0.1 \mathrm{HCCN}$ do not change, which suggest that the treatment with $\mathrm{HCl}$ does not change the structure of the samples. Only the concentration of $\mathrm{K}^{+}$changes from $0.81 \%$ in $0.01 \mathrm{HCCN}$ to $0.57 \%$ in $0.1 \mathrm{HCCN}$.

crystallinity and a suitable $\mathrm{K}^{+}$doping concentration, which suggested the most efficient separation of photogenerated carriers. This result was further proven by EIS. Fig. 7b shows that $0.1 \mathrm{HCCN}$ exhibits the smallest semicircular Nyquist plot, compared with those of the other samples, which indicates enhanced photocatalytic activity.

\subsection{Photocatalytic activities of the samples}

The HERs were measured in TEOA (10 vol\%) solution for 1 $\mathrm{h}$ light irradiation by loading $3 \%$ platinum as a co-catalyst. As shown in Fig. 8a, obviously, both CCN and $x$ HCCN exhibit en-

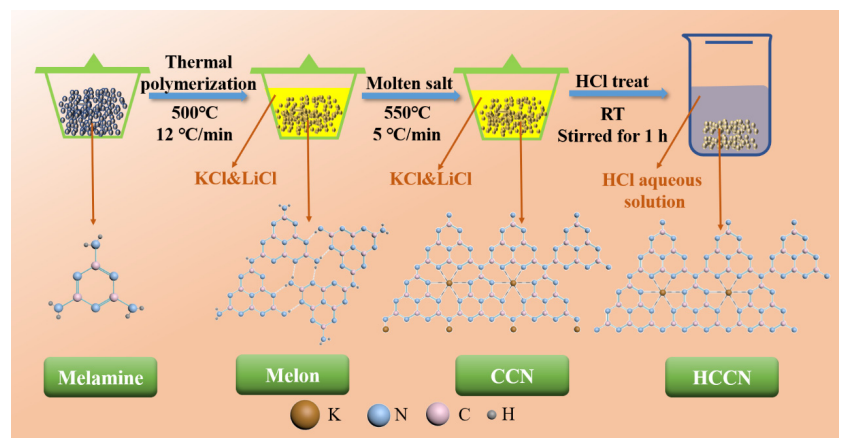

Fig. 6. Possible synthesis process of HCCN by molten-salt method and aqueous $\mathrm{HCl}$ solution treatment. In the first step $\left(500{ }^{\circ} \mathrm{C}, 12{ }^{\circ} \mathrm{C} \mathrm{min}-1\right)$, the melamine molecules polymerize to form heptazine nitride $\mathrm{CN}$ frameworks with a large number of hydrogen bonds and amino groups. In the second step $\left(550{ }^{\circ} \mathrm{C}, 5^{\circ} \mathrm{C} \mathrm{min}-1\right)$, CCN with a large amount of $\mathrm{K}^{+}$is synthesized. In the last step (treatment with $\mathrm{HCl}$ ), HCCN is obtained because some of the $\mathrm{K}^{+}$in the CCN frameworks have been removed and the polymerization sites released, which further enhance the crystallinity of CCN. hanced HERs compared with BCN. Moreover, in the case of $x \mathrm{HCCN}$, the HER gradually increased with the increase in the aqueous $\mathrm{HCl}$ concentration from 0.005 to $0.1 \mathrm{~mol} \mathrm{~L}^{-1}$. This finding was attributed to the excess amount of $\mathrm{K}^{+}$in the $0.005 \mathrm{HCCN}$ sample, which occupied the polymerization and active sites of the photocatalytic reaction, which resulted in undesirable crystallinity and photocatalytic activity. However, with the increase in the concentration of the aqueous $\mathrm{HCl}$ solution, the polymerization and active sites of the photocatalytic reaction were gradually released, which led to increased crystallinity and number of active sites for the photocatalytic reaction. Consequently, the HER gradually increased from $0.005 \mathrm{HCCN}$ to $0.1 \mathrm{HCCN}$. However, with the increase in the aqueous $\mathrm{HCl}$ concentration to $0.2 \mathrm{~mol} \mathrm{~L}^{-1}$, the HER rapidly decreased, which probably resulted from an increase in the number of recombination centers of the photogenerated carriers caused by destruction of the structure of the CN framework. Among the $x$ HCCN samples, the HER of 0.1HCCN was the highest at $683.54 \mu \mathrm{mol} \mathrm{h}^{-1} \mathrm{~g}^{-1}$, which was higher than those of BCN and CCN by 2 and 10 times, respectively. The wavelength-dependent HER of $0.1 \mathrm{HCCN}$ was also determined by utilizing different monochromatic lights. Fig. 8b shows that the apparent quantum yield (AQY) was in line with the results obtained from the DRS. Under $420 \mathrm{~nm}$ monochromatic light irradiation, the AQY of $0.1 \mathrm{HCCN}$ was $6.6 \%$ when TEOA solution $(10$ vol\%) was used as the sacrificial agent. Moreover, the sacrificial-dependent HER of 0.1HCCN was also determined. Four reagents, namely glycerinum, TEOA, ethane diamine, and lactic acid, were used as sacrificial agents to compare the photocatalytic activities, which are shown in Fig. 8c. Among these sacrificial agents, the HERTEOA of $0.1 \mathrm{HCCN}$ is the highest, owing to the 

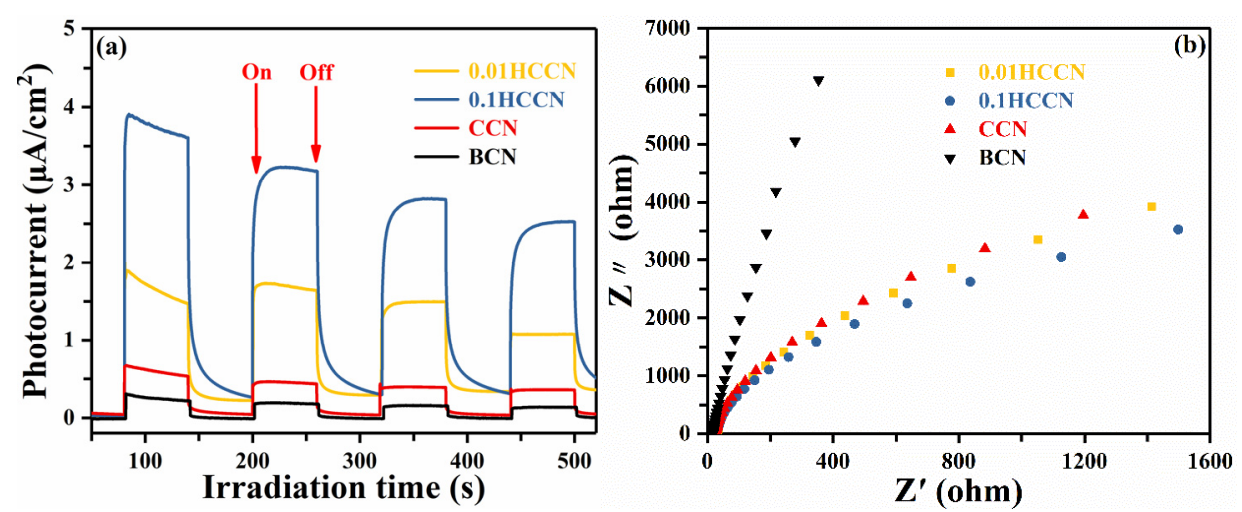

Fig. 7. (a) Photocurrent curves and (b) EIS plots of $0.01 \mathrm{HCCN}, 0.1 \mathrm{HCCN}, \mathrm{CCN}$, and BCN. Both the photocurrent curves and EIS results indicate that $0.1 \mathrm{HCCN}$ exhibits the potential to realize an excellent photocatalytic activity.
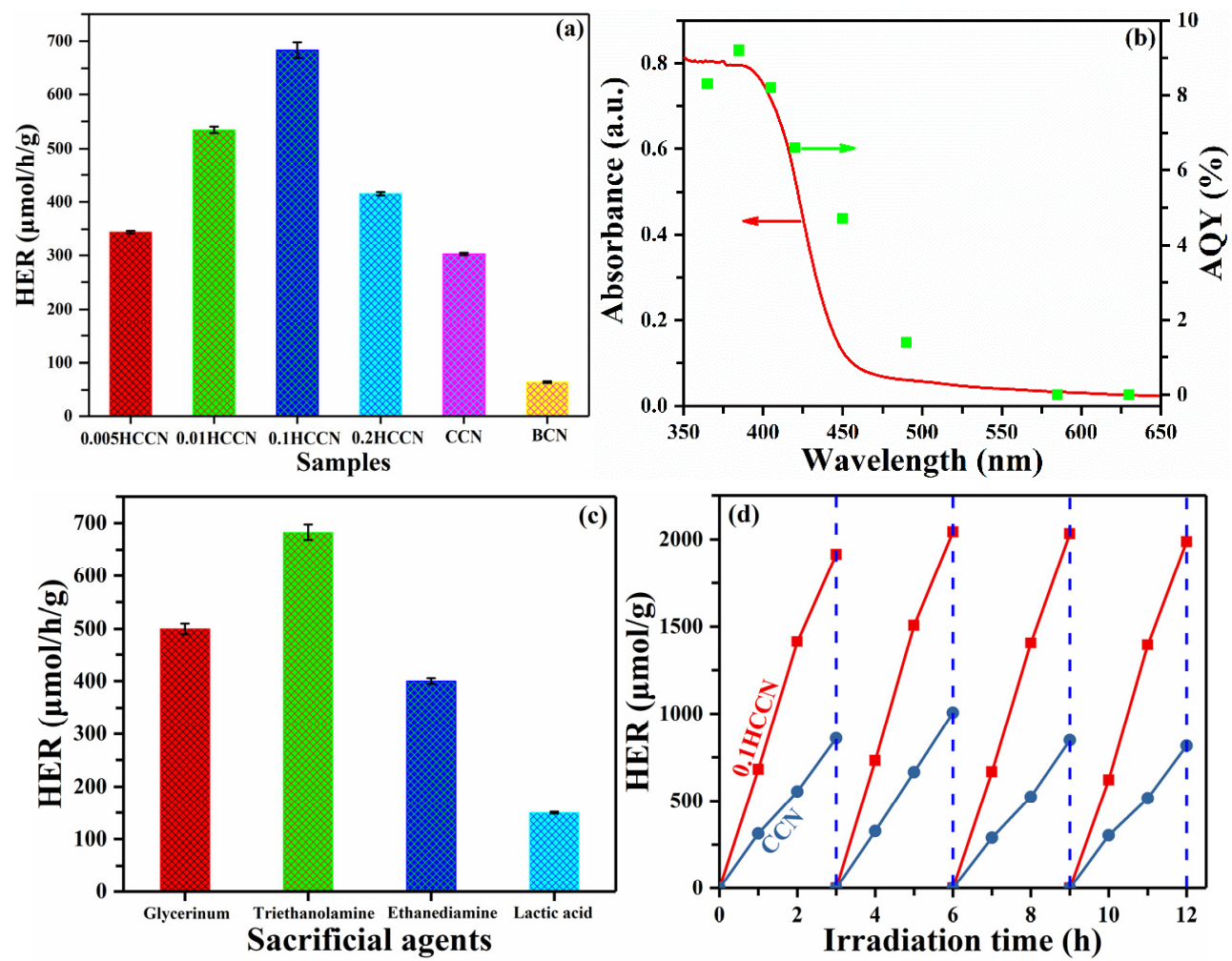

Fig. 8. (a) HERs of the samples loaded with $3 \%$ platinum co-catalyst that were measured under $1 \mathrm{~h}$ light irradiation. TEOA/ $\mathrm{H}_{2} \mathrm{O}(1: 10 \mathrm{vol} \%)$ solution was chosen as the sacrificial agent; (b) Wavelength-dependent HER of $0.1 \mathrm{HCCN}$ under $1 \mathrm{~h}$ monochromatic light irradiation using TEOA/ $\mathrm{H}_{2} \mathrm{O}(1: 10$ vol\%) solution as the sacrificial agent and for $3 \%$ loading of platinum as a co-catalyst; (c) Results of photocatalytic activity tests of $0.1 \mathrm{HCCN}$ loaded with $3 \%$ platinum co-catalyst that were obtained with different sacrificial agents under $1 \mathrm{~h}$ light irradiation; (d) Results of photocatalytic stability tests of $0.1 \mathrm{HCCN}$ and $\mathrm{CCN}$ conducted using TEOA $/ \mathrm{H}_{2} \mathrm{O}(1: 10 \mathrm{vol} \%)$ solution as the sacrificial agent for $3 \%$ loading of platinum as the co-catalyst.

suitable chemical reactivity of TEOA. Finally, the stabilities of the HERs of 0.1HCCN and CCN were studied under $1 \mathrm{~h}$ light irradiation by performing four circulation operations in TEOA (10 vol\%) solution after loading $3 \%$ platinum as the co-catalyst. As shown in Fig. 8d, the HERs of CCN and 0.1HCCN exhibit no obvious decay after four circulation operations, which indicate their satisfactory stabilities in the photocatalytic reactions.

\subsection{Mechanism}

Based on the above results, tentative mechanisms of the roles of $\mathrm{BCN}, \mathrm{CCN}$, and $x \mathrm{HCCN}$ in the photocatalytic reaction were proposed. As shown in Fig. 9, under light irradiation, the samples are excited and produce free electrons and holes. In BCN sample, abundant intralayer hydrogen bonds and amino groups in the covalent $\mathrm{CN}$ framework and radiative charge carriers highly localized within each melon strand are observed, which lead to moderate intralayer transport of the photoinduced carriers [54,61]. As a result, massive recombination of the photogenerated electron-hole pairs occurs over the hydrogen bonds, and BCN exhibits a poor photocatalytic $\mathrm{H}_{2}$ activity. In the case of $\mathrm{CCN}$, the doping sites of $\mathrm{K}^{+}$are in the terminal amino groups and at the interlaminar positions. In primary $\mathrm{CCN}$ (i.e., no $\mathrm{K}^{+}$doping in $\mathrm{CCN}$ ), the valence band (VB) edge 


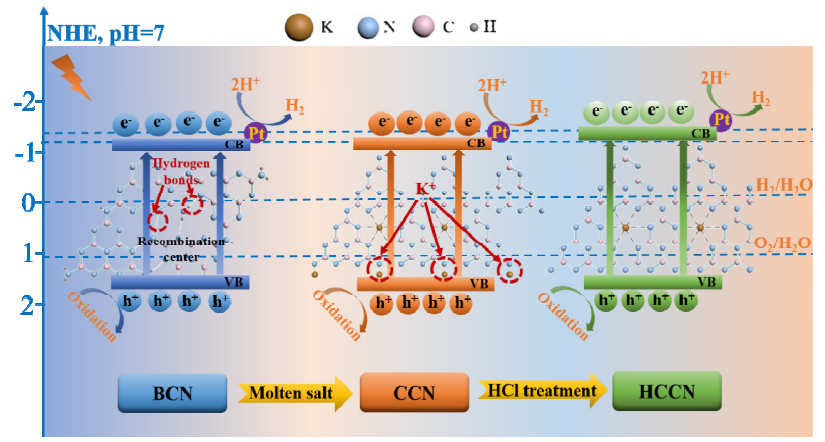

Fig. 9. Schematic of the tentative photocatalytic mechanisms of BCN, CCN, and HCCN. The BCN sample exhibits a moderate photocatalytic performance owing to the existence of hydrogen bonds. The photocatalytic performance of $\mathrm{CCN}$ is restricted because excess of active $\mathrm{K}^{+}$ occupy the activity sites of the photocatalytic reaction. The xHCCN samples exhibit excellent photocatalytic activity owing to their excellent crystallinity and appropriate $\mathrm{K}^{+}$concentration, compared with those of the other samples.

covers all N2 atoms (Fig. S6), and the conduction band (CB) edge comprises $\mathrm{C} 1, \mathrm{C} 2, \mathrm{~N} 2$, and $\mathrm{N} 3$. As a result, the bridging nitrogen (N1) atoms contribute little to the CB and VB edges, which suggests that the $\mathrm{N} 1$ atoms will not be excited to produce photoinduced electrons; thus, the transfer of the photoinduced electrons between the units of heptazine through the $\mathrm{N} 1$ atoms is restrained [62]. When $\mathrm{K}^{+}$are intercalated into the CCN interlayer, adjacent heptazine units can form delivery paths, increase the electronic delocalization, and extend the $\pi$-conjugated systems, which benefit charge-carrier transfer among the heptazine units [63]. However, the $\mathrm{K}^{+}$in the terminal amino groups occupy the polymerization sites of heptazine and the activity sites of the photocatalytic reaction [64]. As a result, CCN exhibits unsatisfactory crystallinity and photocatalytic $\mathrm{H}_{2}$ activity. In the case of $x \mathrm{HCCN}$, the $\mathrm{K}^{+}$in the terminal amino groups are removed with aqueous $\mathrm{HCl}$ solution. Thus, the crystallinity of $x \mathrm{HCCN}$ increases because of the release of the polymerization sites of heptazine, and the photocatalytic $\mathrm{H}_{2}$ activity is enhanced owing to the increase in the number of activity sites for the photocatalytic reaction. Among the $x \mathrm{HCCN}$, 0.1HCCN exhibits the highest photocatalytic $\mathrm{H}_{2}$ activity owing to its excellent crystallinity and appropriate $\mathrm{K}^{+}$concentration, compared with those of the other samples.

\section{Conclusions}

We have successfully prepared a series of HCCN with an appropriate concentration of $\mathrm{K}^{+}$by molten-salt method. The improved crystallinity of the as-prepared samples can decrease the recombination sites of the electron-hole pairs and increase the mobility of the photoinduced carriers through decreases in the surface defects and hydrogen bonds. Moreover, the $\mathrm{K}^{+}$intercalated into the CCN interlayer also enhances the transfer of charge carriers because the former can increase the electronic delocalization and extend the $\pi$-conjugated systems. These features enable $0.1 \mathrm{HCCN}$ with the optimum crystallinity and the appropriate concentration of $\mathrm{K}^{+}$to be obtained; it exhibits an excellent photocatalytic hydrogen evolution of $683.54 \mu \mathrm{mol}$ $\mathrm{h}^{-1} \mathrm{~g}^{-1}$, which is 2 and 10 times those of $\mathrm{CCN}$ and $\mathrm{BCN}$, respectively. A quantum efficiency of $6.6 \%$ was achieved at $420 \mathrm{~nm}$ by using TEOA as the sacrificial agent. This study may provide insights for further improving the light absorption and charge mobility of CCN.

\section{References}

[1] L. Cheng, Q. J. Xiang, Y. L. Liao, H. W. Zhang, Energy Environ. Sci., 2018, 11, 1362-1391.

[2] F. Y. Cheng, H. Yin, Q. J. Xiang, Appl. Surf. Sci., 2017, 391, 432-439.

[3] Y. Xia, Q. Li, K. L. Lv, M. Li, Appl. Surf. Sci., 2017, 398, 81-88.

[4] Q. J. Xiang, F. Y. Cheng, D. Lang, ChemSusChem, 2016, 9, 996-1002.

[5] X. Y. Ma, Q. J. Xiang, Y. L. Liao, T. L. Wen, H. W. Zhang, Appl. Surf. Sci., 2018, 457, 846-855.

[6] Y. Y. Duan, L. Liang, K. L. Lv, Q. Li, M. Li, Appl. Surf. Sci,, 2018, 456, 817-826.

[7] R. C. Shen, C. J. Jiang, Q. J. Xiang, J. Xie, X. Li, Appl. Surf. Sci., 2019, 471, 43-87.

[8] R. C. Shen, J. Xie, Q. J. Xiang, X. B. Chen, J. Z. Jiang, X. Li, Chin. J. Catal., 2019, 40, 240-288.

[9] D. N. Zhang, X. Y. Ma, H. W. Zhang, Y. L. Liao, Q. J. Xiang, Mater. Today Energy, 2018, 10, 132-140.

[10] X. C. Wang, K. Maeda, A. Thomas, K. Takanabe, G. Xin, J. M. Carlsson, K. Domen, M. Antonietti, Nat. Mater., 2009, 8, 76-80.

[11] Y. Li, X. H. Feng, Z. X. Lu, H. Yin, F. Liu, Q. J. Xiang, J. Colloid Interface Sci., 2018, 513, 866-876.

[12] X. P. Wang, Y. X. Chen, M. Fu, Z. H. Chen, Q. L. Huang, Chin. J. Catal., 2018, 39, 1672-1682.

[13] J. W. Fu, Q. L. Xu, J. X. Low, C. J. Jiang, J. G. Yu, Appl. Catal. B, 2019, 243, 556-565.

[14] F. Chen, H. Yang, X. F. Wang, H. G. Yu, Chin. J. Catal., 2017, 38, 296-304

[15] X. F. Wu, J. S. Cheng, X. F. Li, Y. H. Li, K. L. Lv, Appl. Surf. Sci,, 2019, 465, 1037-1046.

[16] Z. Qin, W. J. Fang, J. Y. Liu, Z. D. Wei, Z. Jiang, W. F. Shangguan, Chin. J. Catal., 2018, 39, 472-478.

[17] X. H. Wu, F. Y. Chen, X. F. Wang, H. G. Yu, Appl. Surf. Sci., 2018, 427, 645-653.

[18] K. Maeda, ACS Catal., 2013, 3, 1486-1503.

[19] H. Kato, K. Asakura, A. Kudo, J. Am. Chem. Soc., 2003, 125, 3082-3089.

[20] Y. Ham, K. Maeda, D. Cha, K. Takanabe, K. Domen, Chem. Asian J., 2013, 8, 218-224.

[21] G. Algara-Siller, N. Severin, S. Y. Chong, T. Björkman, R. G. Palgrave, A. Laybourn, M. Antonietti, Y. Z. Khimyak, A. V. Krasheninnikov, J. P. Rabe, U. Kaiser, A. I. Cooper, A. Thomas, M. J. Bojdys, Angew. Chem. Int. Ed., 2014, 53, 7450-7455.

[22] M. K. Bhunia, K. Yamauchi, K. Takanabe, Angew. Chem. Int. Ed., 2014, 53, 11001-11005.

[23] D. Dontsova, C. Fettkenhauer, V. Papaefthimiou, J. Schmidt, M. Antonietti, Chem. Mater., 2016, 28, 772-778.

[24] H. H. Liu, D. L. Chen, Z. Q. Wang, H. J. Jing, R. Zhang, Appl. Catal. B, 2017, 203, 300-313

[25] Y. P. Yuan, L. S. Yin, S. W. Cao, L. N. Gu, G. S. Xu, P. Du, H. Chai, Y. S. Liao, C. Xue, Green Chem., 2014, 16, 4663-4668.

[26] J. Wang, Y. Shen, Y. Li, S. Liu, Y. Zhang, Chem. Eur. J., 2016, 22, 12449-12454.

[27] W. N. Xing, W. G. Tu, Z. H. Han, Y. D. Hu, Q. Q. Meng, G. Chen, ACS Energy Lett., 2018, 3, 514-519.

[28] W. Iqbal, B. C. Qiu, Q. H. Zhu, M. Y. Xing, J. L. Zhang, Appl. Catal. B, 


\section{Graphical Abstract}

Chin. J. Catal., 2020, 41: 21-30 doi: S1872-2067(19)63427-3

Enhanced photocatalytic hydrogen production activity of highly crystalline carbon nitride synthesized by hydrochloric acid treatment

Yang Li, Dainan Zhang, Xionghan Feng, Quanjun Xiang*

University of Electronic Science and Technology of China; Huazhong Agricultural University

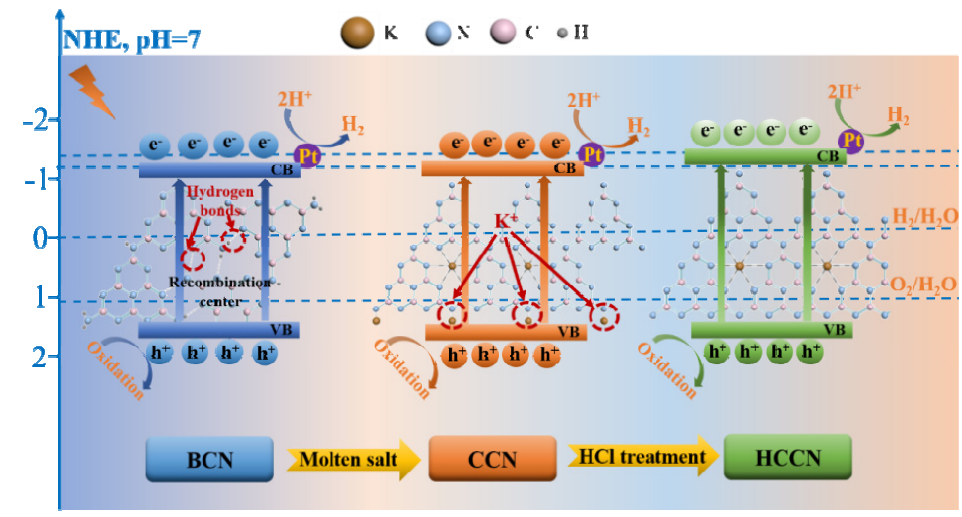

Highly crystalline carbon nitride, prepared by a molten-salt method with aqueous hydrochloric acid solution treatment, exhibited an enhanced photocatalytic $\mathrm{H}_{2}$ production activity.

2018, 232, 306-313.

[29] L. H. Lin, Z. Y. Yu, X. C. Wang, Angew. Chem. Int. Ed., 2019, 58, 6164-6175.

[30] G. Li, W. H. Chang, Y. Yang, Nat. Rev. Mater., 2017, 2, 17043.

[31] D. Kim, A. Osuka, Acc. Chem. Res., 2004, 37, 735-745.

[32] Z. X. Zeng, H. T. Yu, X. Quan, S. Chen, S. S. Zhang, Appl. Catal. B, 2018, 227, 153-160.

[33] L. H. Lin, W. Ren, C. Wang, A. M. Asiri, J. Zhang, X. C. Wang, Appl. Catal. B, 2018, 231, 234-241.

[34] J. Y. Liu, W. J. Fang, Z. D. Wei, Z. Qin, Z. Jiang, W. F. Shangguan, Appl. Catal. B, 2018, 238, 465-470.

[35] K. He, J. Xie, M. Li, X. Li, Appl. Surf. Sci., 2018, 430, 208-217.

[36] Y. H. Li, K. L. Lv, W. K. Ho, Z. W. Zhao, Y. Huang, Chin. J. Catal., 2017, 38, 321-329.

[37] P. Chen, F. Dong, M. X. Ran, J. R. Li, Chin. J. Catal., 2018, 39, 619-629.

[38] C. F. Yang, W. Teng, Y. H. Song, Y. J. Cui, Chin. J. Catal., 2018, 39, 1615-1624.

[39] Q. L. Xu, C. J. Jiang, B. Cheng, J. G. Yu, Dalton Trans., 2017, 46, 10611-10619.

[40] B. Kurpil, A. Savateev, V. Papaefthimiou, S. Zafeiratos, T. Heil, S. Özenler, D. Dontsova, M. Antonietti, Appl. Catal. B, 2017, 217, 622-628.

[41] Y. J. Zhang, A. Thomas, M. Antonietti, X. C. Wang, J. Am. Chem. Soc., 2009, 131, 50-51

[42] Y. Wu, M. Wen, M. Navlani-García, Y. Kuwahara, K. Mori, H. Yamashita, Chem. Asian J., 2017, 12, 860-867.

[43] A. B. Jorge, D. J. Martin, M. T. S. Dhanoa, A. S. Rahman, N. Makwana, J. Tang, A. Sella, F. Corà, S. Firth, J. A. Darr, P. F. McMillan, J. Phys. Chem. C, 2013, 117, 7178-7185.

[44] B. Chai, C. Liu, J. T. Yan, Z. D. Ren, Z. J. Wang, Appl. Surf. Sci., 2018, 448, 1-8.

[45] J. W. Fu, J. G. Yu, C. J. Jiang, B. Cheng, Adv. Energy Mater., 2018, 8, 1701503
[46] B. Chai, J. T. Yan, C. L. Wang, Z. D. Ren, Y. C. Zhu, Appl. Surf. Sci., 2017, 391, 376-383.

[47] H. Tan, X. M. Gu, P. Kong, Z. Lian, B. Li, Z. F. Zheng, Appl. Catal. B, 2019, 242, 67-75.

[48] H. Gao, S. Yan, J. Wang, Y. A. Huang, P. Wang, Z. Li, Z. Zou, Phys. Chem. Chem. Phys., 2013, 15, 18077-18084.

[49] G. Zhang, G. Li, Z. A. Lan, L. Lin, A. Savateev, T. Heil, S. Zafeiratos, X. C. Wang, M. Antonietti, Angew. Chem. Int. Ed., 2017, 56, 13445-13449.

[50] L. Wang, X. Duan, G. Wang, C. Liu, S. Luo, S. Zhang, Y. Zeng, Y. Xu, Y. Liu, X. Duan, Appl. Catal. B, 2016, 186, 88-96.

[51] X. Dou, Z. Lin, H. Chen, Y. Zheng, C. Lu, J. M. Lin, Chem. Commun., 2013, 49, 5871-5873.

[52] C. Q. Xu, K. Li, W. D. Zhang, J. Colloid Interface Sci., 2017, 495, 27-36.

[53] P. F. Xia, M. J. Liu, B. Cheng, J. G. Yu, L. Y. Zhang, ACS Sustainable Chem. Eng., 2018, 6, 8945-8953.

[54] H. H. Ou, L. H. Lin, Y. Zheng, P. J. Yang, Y. X. Fang, X. C. Wang, $A d v$. Mater., 2017, 29, 1700008.

[55] G. Zhang, J. Zhang, M. Zhang, X. Wang, J. Mater. Chem., 2012, 22, 8083-8091.

[56] K. Schwinghammer, M. B. Mesch, V. Duppel, C. Ziegler, J. Senker, B. V. Lotsch, J. Am. Chem. Soc., 2014, 136, 1730-1733.

[57] Z. Chen, S. Pronkin, T. P. Fellinger, K. Kailasam, G. Vile, D. Albani, F. Krumeich, R. Leary, J. Barnard, J. M. Thomas, J. Perez-Ramirez, M. Antonietti, D. Dontsova, ACS Nano, 2016, 10, 3166-3175.

[58] Y. F. Guo, J. Li, Y. P. Yuan, L. Li, M. Y. Zhang, C. Y. Zhou, Z. Q. Lin, Angew, Chem. Int. Ed., 2016, 55, 14693-14697.

[59] J. Liu, Y. Liu, N. Liu, Y. Han, X. Zhang, H. Huang, Y. Lifshitz, S. T. Lee, J. Zhong, Z. Kang, Science, 2015, 347, 970-974.

[60] D. Dontsova, S. Pronkin, M. Wehle, Z. Chen, C. Fettkenhauer, G. Clavel, M. Antonietti, Chem. Mater., 2015, 27, 5170-5179.

[61] Y. Kang, Y. Yang, L. C. Yin, X. Kang, L. Wang, G. Liu, H. M. Cheng, Adv. Mater., 2016, 28, 6471-6477. 
[62] B. C. Zhu, L. Y. Zhang, B. Cheng, J. G. Yu, Appl. Catal. B, 2018, 224, 983-999.

[63] T. Xiong, W. L. Cen, Y. X. Zhang, F. Dong, ACS Catal., 2016, 6,
$2462-2472$.

[64] Y. Y. Wang, S. Zhao, Y. W. Zhang, J. S. Fang, Y. M. Zhou, S. H. Yuan, C. Zhang, W. X. Chen, Appl. Surf. Sci., 2018, 440, 258-265.

\title{
盐酸处理制备高结晶氮化碳及其增强光催化产氢活性 \\ 李 阳 ${ }^{\mathrm{a}, \mathrm{b}}$, 张岱南 ${ }^{\mathrm{a}}$, 冯雄汉 ${ }^{\mathrm{b}}$, 向全军 ${ }^{\mathrm{a}}$ * \\ ${ }^{a}$ 电子科技大学电子科学与工程学院电子薄膜与集成器件国家重点实验室, 四川成都610054 \\ 华中农业大学资源与环境学院, 湖北武汉 430070
}

\begin{abstract}
摘要: 由于氢气燃烧具有高能量和零污染的优点, 氢能一直被认为是解决环境污染和全球能源危机问题的新能源. 而光催 化剂可以将太阳能转化为氢能, 是目前制氢最理想的方式. 近年来, 研究者们的目光已经转向非金属光催化剂, 其中氮化 碳光催化剂因其化学稳定性好、成本低和无毒性而备受关注. 但是传统的利用含氮前驱体通过热聚合得到的氮化碳呈无 定形或半结晶结构, 导致其光催化活性很差. 而熔盐法制备的结晶氮化碳 $(\mathrm{CCN})$ 则具有优异的光催化产氢性能. 但是, 熔盐 法得到的 $\mathrm{CCN}$ 依然没达到理想的结晶度.

在本文中, 我们用盐酸 $(\mathrm{HCl})$ 洗涤处理熔盐法制备的产物,进一步提高了 $\mathrm{CCN}$ 的结晶度. 结果表明, 随着盐酸水溶液浓 度的增加, 制备样品的结晶度增大, 在盐酸浓度为 $0.1 \mathrm{~mol} / \mathrm{L}$ 时, 样品结晶度达到最大值. 这是因为盐酸水溶液可以去除 $\mathrm{CCN}$ 末端氨基中的一些钾离子, 导致聚合位点被释放, 所以进一步提高了样品的结晶度. 而当盐酸浓度进一步提高到 0.2 $\mathrm{mol} / \mathrm{L}$ 时, 氮化碳结构因为过高的盐酸浓度被破坏, 导致结晶度反而下降. 以 $0.1 \mathrm{~mol} / \mathrm{L}$ 盐酸水溶液处理得到的 $0.1 \mathrm{HCCN}$ 样品 具有良好的光催化产氢性能, 在以三乙醇胺为牺牲剂时, 其光催化产氢速率达到 $683.54 \mu \mathrm{mol} \mathrm{h}^{-1} \mathrm{~g}^{-1}$, 在 $420 \mathrm{~nm}$ 处的量子效 率为 $6.6 \%$, 光催化产氢速率分别是 $\mathrm{CCN}$ 和块状氮化碳的 2 倍和 10 倍. 光催化活性的提高主要有两个原因: 样品结晶度的提 高和钾离子嵌入 $x \mathrm{HCCN}$ 样品的中间层. 其中, 样品结晶度的提高可以减少样品中的表面缺陷以及破坏结构中的氢键, 从而 增加了光生载流子的迁移, 减少了电子空穴对的复合位点, 这都非常有利于光催化反应的进行. 而插入到 $x \mathrm{HCCN}$ 中间层的 钾也促进了光生电子的转移. 这是因为桥连的氮原子(N1)并不会被激发产生光生电子, 因此抑制了光生电子在七嗪单元之 间的迁移, 而插入到 $x \mathrm{HCCN}$ 中间层的 $\mathrm{K}$ 可以增加电子的离域性, 延长 $\pi$ 共轭体系, 从而促进光生电子的转移, 进一步提高光 催化产氢活性. 本研究为熔盐法的进一步发展提供了新的思路.
\end{abstract}

关键词: 晶化氮化碳; 熔盐法; 光催化析氢; 钾离子; 盐酸水溶液

收稿日期: 2019-04-30. 接受日期: 2019-05-27. 出版日期: 2020-01-05.

*通讯联系人. 电话/传真: (028)83207063; 电子信箱: xiangqj@uestc.edu.cn

基金来源：国家自然科学基金(51672099，21403079); 四川省科技计划(2019JDRC0027); 中央高校基本科研业务费专项基金 (2017-QR-25).

本文的电子版全文由Elsevier出版社在ScienceDirect上出版(http://www.sciencedirect.com/science/journal/18722067). 